\title{
O ESTÁGIO OBRIGATÓRIO EM UM CURSO DE BACHARELADO EM EDUCAÇÃO FÍSICA
}

\author{
Jonathan Barra Pereira \\ Deniele Pereira Batista \\ Carlos Alberto de Andrade Coelho Filho \\ Universidade Federal de Juiz de Fora (UFJF), Juiz de Fora, Minas \\ Gerais, Brasil
}

\begin{abstract}
RESUMo: Esta pesquisa objetiva discutir o estágio obrigatório oferecido pelo curso de bacharelado em educação física da Universidade Federal de Juiz de Fora, tendo o seu foco direcionado às contribuições e limitações associadas ao processo de formação profissional. Dez graduandos que já haviam completado, no mínimo, duas disciplinas de estágio obrigatório no curso, foram entrevistados. Princípios da entrevista compreensiva nortearam os procedimentos de coleta, análise e interpretação de dados. Concluímos que a conexão entre as instituições do campo profissional e a universidade, limitada a aspectos legais e administrativos, não contribui para que o estágio aflore em todo o seu potencial.
\end{abstract}

Palavras-Chave: Educação. Educação Física. Estágio. Formação profissional.

INTRODUÇÃO

A Universidade Federal de Juiz de Fora (UFJF), sediada em Juiz de Fora (MG), assume a responsabilidade de regulamentar os estágios para os cursos superiores a ela vinculados, conforme estabelece $\circ \S 3^{\circ}$ do art. 47 do Regulamento Acadêmico da Graduação (RAG), norteada pela Lei Federal no 11.788 de Regulamentação do Estágio, de 25 de setembro de 2008. Os cursos superiores oferecidos pela UFJF são autônomos no processo de elaboração dos estágios em seus respectivos Projetos Pedagógicos de Curso (PPC), de acordo com $\S 1^{\circ}$ do art. 47 do RAG, no sentido de que possam considerar o que é pertinente às diferentes áreas. Portanto, com o propósito de discutir as questões específicas relativas ao estágio, de acordo com o RAG (art. 48 e $\S 3^{\circ}$ do art. 50), cada curso deve possuir uma Comissão de Orientação de Estágio (COE).

Observemos o que explicita a Lei Federal no 11.788, acerca do estágio:

Art. 1. Estágio é ato educativo escolar supervisionado, desenvolvido no ambiente de trabalho, que visa à preparação para o trabalho produtivo de educandos que estejam frequentando o ensino regular em instituições de educação superior, de educação profissional, de 
ensino médio, da educação especial e dos anos finais do ensino fundamental, na modalidade profissional da educação de jovens e adultos.

$\S 1^{\circ}$. O estágio faz parte do projeto pedagógico do curso, além de integrar o itinerário formativo do educando.

$\$ 2^{\circ}$. O estágio visa ao aprendizado de competências próprias da atividade profissional e à contextualização curricular, objetivando o desenvolvimento do educando para a vida cidadã e para o trabalho (BRASIL, 2008, p.3).

No interior da proposta de estágio curricular para o curso de bacharelado em educação física oferecido pela Faculdade de Educação Física e Desportos (FAEFID) da UFJF, consta que os estágios são:

[...] uma forma de complementar o ensino e a aprendizagem acadêmica; devem ser planejados, executados, acompanhados e avaliados em conformidade com os currículos, programas e calendários escolares, a fim de se constituírem em instrumentos de integração, em termos de treinamento prático, de aperfeiçoamento técnico-cultural, científico e de relacionamento humano (UNIVERSIDADE FEDERAL DE JUIZ DE FORA, 2010, p.1).

Conforme orientações contidas nos documentos acima citados, devem ser garantidas algumas condições para que o estágio possa se efetivar como um componente importante no âmbito da formação profissional: ato educativo escolar supervisionado, como integrante do ensino e da aprendizagem acadêmicas; preparação para o trabalho; realização no campo de trabalho; desenvolvimento de competências próprias da atividade profissional; contextualização com o currículo e o campo profissional.

Decerto, o estágio desempenha um importante papel na formação e preparação do futuro profissional. Contudo, parece ainda apresentar problemas que comprometem o seu desenvolvimento qualitativo, dentre os quais destacam-se: a falta de clareza em sua organização e o seu desenvolvimento nas instituições (GATTI, 2010; ZABALZA, 2011); a ausência de integração com os demais componentes curriculares (GATI, 2010; PIMENTA; LIMA, 2006); a falta de conexão entre a universidade e o campo profissional, bem como entre os profissionais atuantes nestas instâncias (CALDERANO, 2013; GATTI, 2010; LÜDKE, 2013; ZEICHNER, 2010).

Para Gatti (2010), a carga horária obrigatória dos estágios supervisionados propicia aos alunos um contato mais próximo com o campo profissional. Entretanto, essa mesma possibilidade carrega em si um problema: Gatti e Barreto (2009) constatam a falta de planos ou projetos de estágio e acentuam serem quase inexistentes as instituições que especificam as orientações que subsidiam os estágios. Em direção similar, Zabalza (2011, p. 27) elabora: "[...] la ausencia de un modelo claro que defina la organización del Practicum ${ }^{1}$ es, en mi opinión, la variable que mejor explica la heterogeneidad, dispersión y falta de eficacia de muchos modelos de prácticas actualmente vigentes".

Zeichner (2010) observa que as experiências do campo profissional proporcionam importantes ocasiões de efetiva aprendizagem, que as atividades 
cuidadosamente orientadas e coordenadas com o curso favorecem a qualidade dos estágios, mas ressalta também que os "tradicionais modelos" (p. 485) de estágio não têm superado alguns obstáculos referentes ao processo de aprendizagem devido ao planejamento e monitoramento inadequado das atividades. De fato, a falta de conexão entre os cursos de formação e o campo profissional é sublinhada. $O$ autor destaca as dificuldades dos professores universitários em orientarem os estagiários de acordo com as atividades planejadas no campo profissional, e as dificuldades dos "professores supervisores" ${ }^{12}$ de conseguirem orientar de acordo com as disciplinas cursadas pelo estagiário no contexto universitário. Ou seja, por um lado as condições de trabalho do supervisor do estágio no campo profissional não contribuem para que um estágio de qualidade possa ser efetivado, por outro, conforme Pires (2012), o professor orientador parece não encontrar, na universidade, condições favoráveis para fazer o acompanhamento dos estagiários.

Ainda no que tange à falta de conexão entre as instituições formadoras, Zabalza (2011) observa que quando se compreende, na universidade, que o seu papel é apenas o de enviar estudantes a centros de trabalho, parece óbvio que os problemas que devem ser resolvidos são, basicamente, de ordem organizativa. $O$ autor esboça um diagnóstico: "Pero el problema aparece cuando las instituciones se detienen en ese nivel de desarrollo del Practicum, quizás porque carecen de referentes, de planes estratégicos o de voluntad institucional para proponerse objetivos más avanzados" (ZABALZA, 2011, p. 31).

Em termos sumários, os autores consultados nos dizem que o estágio possui problemas que merecem ser enfrentados: o distanciamento entre o campo profissional e a universidade; a falta de clareza dos métodos utilizados por professores orientadores e por supervisores do estágio no campo profissional; a carência de aprofundamento conceitual relacionada às atividades a serem realizadas pelos estagiários; as dificuldades de acompanhamento do estagiário no campo de estágio; a inexistência de um programa de estágio que zele por sua organização.

Como registrado acima, na Faculdade de Educação Física e Desportos da Universidade Federal de Juiz de Fora (FAEFID/UFJF), os estágios, em tese ou no papel, seguem as orientações da Lei de Estágio, do RAG e da própria proposta de estágio elaborada pela unidade acadêmica para a formação do bacharel. Assim, ao considerarmos, de um lado, as evidências associadas à importância do estágio para a formação profissional e, de outro, os problemas relacionados ao mesmo, ficam as questões: qual a parcela de contribuição dos estágios obrigatórios cursados na FAEFID/UFJF para a formação do bacharel em educação física? Como os problemas anteriormente listados têm se manifestado nos estágios obrigatórios cursados no interior do curso de bacharelado em educação física da UFJF?

Considerando, portanto, o problema anteriormente delineado e as questões apresentadas, o objetivo deste artigo é discutir o estágio obrigatório oferecido pelo curso de bacharelado em educação física da Universidade Federal de Juiz de Fora, tendo o seu foco direcionado às contribuições e limitações associadas ao processo de formação profissional.

\section{MetOdOLOGIA}


Esta pesquisa, de natureza qualitativa, teve seu projeto aprovado pelo Comitê de Ética em Pesquisa Humana da Universidade Federal de Juiz de Fora (Parecer $n^{\circ} 1.681 .149$ ). Contou com a participação de dez graduandos do curso de bacharelado em educação física da UFJF. Para a composição do grupo de participantes, os seguintes critérios de inclusão foram utilizados: 1$)$ ser aluno dos três últimos períodos $\left(6^{\circ}, 7^{\circ}, 8^{\circ}\right)$ do curso de bacharelado em educação física da UFJF; 2) ter completado, no mínimo, duas disciplinas de estágio obrigatório; 3 ) prontificar-se a participar, livremente, da pesquisa (assinando o Termo de Consentimento Livre e Esclarecido).

$O$ instrumento utilizado para coleta de dados foi a entrevista. O roteiro de questões que norteou as reflexões durante as entrevistas é o seguinte: 1.0 que é o estágio para você? 2. Qual a importância que os estágios tiveram na sua formação profissional? 3. Quanto à organização dos estágios, quais considerações você faria? 4. Quais considerações você faria sobre os locais dos estágios por você vivenciados? 5 . Com base em suas experiências, quais considerações você faria sobre os métodos utilizados por professores orientadores e supervisores do estágio no campo profissional? 6. Tendo por base as suas experiências com o estágio, você considera que o curso de formação universitária e o campo profissional conseguem estabelecer uma conexão de forma a contribuir com a formação do profissional? 7. Existem aspectos que dificultaram a sua dedicação aos estágios, o seu envolvimento com os mesmos, a sua motivação? 8. Tendo por base as experiências vivenciadas por você nos estágios obrigatórios do bacharelado, como pode avaliar a contribuição dos mesmos para a sua formação profissional? 9. Tem mais algum elemento que gostaria de acrescentar relacionado aos estágios por você vivenciados?

As entrevistas, registradas em um minigravador, ocorreram em dia, horário e local de maior conveniência para os participantes. A coleta de dados foi interrompida mediante a consideração de que as informações captadas atingiram um ponto de redundância, isto é, estavam suficientemente confirmadas e com poucas possibilidades de emergirem novas informações relevantes que justificassem a continuidade da coleta.

Princípios da "entrevista compreensiva" (KAUFMANN, 2013) nortearam os procedimentos de coleta, análise e interpretação de dados. Desses princípios, destaquese a busca por um tom, durante a realização das entrevistas, muito mais próximo de uma conversa entre iguais do que aquele do questionário administrado de cima para baixo. Tal dinâmica proporcionou que estabelecêssemos uma troca de ideias em torno do tema com os entrevistados. Considere-se ainda a importância, na entrevista compreensiva, de que o pesquisador esteja ativamente envolvido nas questões, para provocar o envolvimento do entrevistado.

O autor observa:

[...] a condução de entrevistas, ainda que seja um momento excepcional e muito difícil de ser realizado perfeitamente, não constituiu a fase mais importante da pesquisa. Esta vem em seguida, com a análise do material, segunda parte da investigação, verdadeiro ponto de partida do trabalho de aprofundamento, e que pode recuperar largamente as fraquezas da fase precedente (KAUFMANN 2013, p. 118). 
Quanto ao processo analítico, registre-se a importância de o pesquisador se deixar surpreender pelo material coletado e valorizar as articulações entre os diferentes níveis de reflexão por ele proporcionados. A título de exemplo, escutando e reescutando as gravações, quantas vezes forem necessárias, por compreender que cada audição é uma audição diferente, e que em singular investida elementos novos Ihe tocarão, aspectos não antes percebidos emergirão e proporcionarão pensamentos até então inusitados. Mais ainda, nessa dinâmica não se pode perder de vista a indispensabilidade em "correr o risco da interpretação" (KAUFMANN, 2013, p. 146), pois não há pesquisa possível sem ela. Ressalte-se também que o resultado não depende do conteúdo, simples matéria-prima, mas da capacidade analítica do pesquisador. Como acentua Kaufmann (2013), é preciso fazer os fatos falarem, encontrar indícios, interrogar-se a respeito da mínima frase.

Durante o processo analítico, ideias-chave emergiram com maior intensidade, o que nos permitiu organizar o estudo a partir dos seguintes termos: "programa de estágio: organização e desenvolvimento" e "professores orientadores e supervisores do estágio no campo profissional". Este artigo, contudo, se ocupa especificamente da discussão sobre o primeiro termo.

Os entrevistados são identificados, na sequência do trabalho, pela letra $E$, seguida dos números 1 a 10; ou seja, o participante 1 é identificado como E1, e assim sucessivamente.

\section{PROGRAMA DE ESTÁGIO: ORGANIZAÇÃO E DESENVOLVIMENTO}

Para Zabalza ${ }^{3}$ (2014), o estágio é a oportunidade de o estudante aplicar, compreender e desenvolver conhecimentos e habilidades no campo profissional. $O$ autor ressalta que o estágio permite e oferece a aproximação e a aplicação dos conhecimentos a contextos reais, diferenciados do acadêmico. Observemos o que dizem os entrevistados: "O estágio é uma forma de você aprender, ter a vivência fora da faculdade com o que você aprendeu na teoria" (E8).

\footnotetext{
Para mim seria um espaço que a gente teria para entrar em contato com o meio profissional. A atuação do profissional ali, para a gente poder observar primeiro, aprender e a partir da troca de conhecimentos poder atuar numa parte (E3).

O estágio é a colocação na prática dos conhecimentos que a gente adquire na faculdade. Aqui a gente vê a teoria também atrelada à prática, mas no estágio a gente consegue colocar esses conhecimentos mais é na prática (E2).
}

Podemos perceber que os relatos nos direcionam para a relação do estágio com a prática profissional. Pimenta (1995) observa que o exercício de qualquer profissão é prático, no sentido de agir ou fazer, e se o curso de formação tem como papel preparar o futuro profissional para exercer uma profissão, é apropriado "que se tenha a preocupação com a prática" (p. 28). Entretanto, vale observar o que indicam Pimenta e Lima (2012) acerca do afastamento que se deve exercer de certa compreensão que associa o estágio à parte prática do curso. Assim, na tentativa de superação da dicotomia teoria e prática, as autoras compreendem "[...] que o estágio não é atividade prática, é atividade teórica de 
conhecimento, fundamentação, diálogo e intervenção na realidade, esta, sim, objeto das práxis" $^{4 \prime \prime}$ (PIMENTA; LIMA, 2012, p. 45). Nesse sentido, o estágio deve ser visto como eixo de articulação e reflexão entre teoria e prática (CALDERANO, 2012; KULCSAR, 1994; LÜDKE, 2013; PIMENTA, 1995; PEREIRA; PEREIRA, 2012; PIMENTA; LIMA, 2006). Acrescentese então que o estágio não deve ser enfrentado como "[...] tarefa burocrática a ser cumprida formalmente" (KULCSAR, 1994, p. 65). O relato a seguir nos indica justamente o contrário, isto é, o distanciamento entre a instituição do campo profissional (instituição concedente) e a universidade; mais ainda, o distanciamento entre o que se encontra registrado nos documentos oficiais e o que se efetiva no estágio:

[...] as instituições concedentes têm um convênio aqui com a universidade, mas não existe uma aproximação [...]. Não existe uma ligação entre elas a não ser no papel, burocrática. No papel existe, mas não tem. Eu acho que muitos professores daqui não conhecem os professores que estão nesses estabelecimentos e vice-versa (E5).

Para Sousa e Lessa (2012, p. 159), a organização e o envio da documentação comprobatória dos estágios representam momentos de grandes desafios e dificuldades, pois a não observância da quantidade de documentos exigidos, da entrega dos mesmos sem erros e em tempo hábil, pode levar até à reprovação dos alunos. De fato, trata-se de uma situação destacada pelos entrevistados:

Eu acho que a maior dificuldade é a questão burocrática, é muito papel. Você tem que levar o papel para os professores assinarem, depois você tem que levar lá na central de atendimento, depois o papel volta para a FAEFID para aprovação. Caso seja aprovado, ele volta para a central de atendimento; caso não seja aprovado, você tem que fazer o mesmo processo novamente. $\mathrm{E}$ isso com certeza é a maior dificuldade. Eu acho que isso podia ser simplificado porque acaba que você perde muito tempo nessa questão e até às vezes perde os estágios por causa disso (E4).

A burocracia é... triste. Então, não sei se eu posso falar isso, mas eu sempre iniciei [o estágio] antes de liberar tudo. Eu comecei a fazer na primeira semana de aula. Eu já corri atrás antes de começar as aulas, para saber o que eu queria fazer, para conversar com o professor [...]. Só que até hoje o meu documento está assim. Eu perdi um tempão por causa de assinatura, aí perderam meu plano e deu a maior confusão, e está até hoje (E10).

Constata-se então que os discentes vivenciam momentos de tensão ao lidar com a documentação necessária para a formalização e realização dos estágios. É uma burocracia que pode impactar em razão das possibilidades de atraso no início do estágio e até mesmo a sua não conclusão no semestre letivo, o que implica nova matrícula na disciplina em semestre subsequente, novo encaminhamento de documentação etc.

Mas um dos entrevistados compreende o valor da burocracia: "Eu vejo como necessário ter essa parte burocrática, vamos dizer assim, ter que fazer num lugar que tem 
vínculo com a universidade, de ter que fazer tudo, os papéis, a documentação, porque é uma coisa formal" (E1). O depoimento nos remete para o que assinala Zabalza (2014) sobre a importância do vínculo (convênios, contratos, acordos) com as instituições concedentes de estágio: de um lado para que essa etapa formativa se processe a bom termo, de outro para que fiquem explicitados os direitos e os deveres de ambas as partes. E o discente acrescenta aspectos que merecem ser elaborados, relacionados às orientações fornecidas nessa etapa da formação e à burocracia:

Eu vejo um pouco como confuso para quem não fez o estágio ainda, assim como os primeiros estágios que fiz. Eu tive um pouco de dificuldade por causa disso [burocracia], mas eu vejo isso como necessário e acho que uma forma de melhorar seria ter mais orientação quanto a isso (E1).

Agostini (2008) reforça a importância de se estabelecer convênios bem elaborados - e, se necessário, reelaborados - para que os serviços relacionados aos estágios sejam cumpridos, bem como para facilitar o acesso dos estagiários aos respectivos locais de estágio. Podemos então compreender que os documentos, quando adequadamente pensados no contexto do estágio, contribuem na orientação dos estagiários e na organização da disciplina.

Outros entrevistados são mais categóricos em evidenciar as dificuldades relacionadas às orientações: "No quinto período a gente não tem uma orientação. A gente não tem uma disciplina ou uma reunião no começo do período que explique sobre o estágio" (E5). ${ }^{5}$

Quando eu cheguei no quinto período, não tive [orientação], eu nem sabia o que tinha que fazer. Assim, em termos de documentação, eu sei que existe no site da UFJF uma cartilha com várias orientações e tal, mas quando a gente chega para fazer os estágios ninguém fala que existe isso no site. Então, assim, já começou aí que eu desisti de fazer os estágios no $5^{\circ}$ período (E3).

Em que pese o longo caminho a ser trilhado pelos alunos para o cumprimento das quinhentas horas de estágio, constata-se que as dificuldades relacionadas às orientações emergem antes mesmo de a jornada ter, objetivamente, iniciado. Evidenciase, assim, uma falha nas estratégias adotadas pelo curso em questão, e em especial pelos responsáveis a orientar os discentes no interior deste curso (Comissão de Orientação de Estágio), quanto à iniciação no estágio, associada especialmente à lida com os documentos exigidos, e a burocracia.

Quanto aos problemas externados pelos entrevistados, pode ser possível amenizá-los, conforme sugerem Sousa e Lessa (2012), propondo oficinas, no início de cada semestre letivo, que auxiliem com o "preenchimento dos documentos, destacando item por item, explicando a função e os objetivos de cada um" (p. 159).

Lüdke (2013), por sua vez, avalia que o "manual de estágio", sendo bem elaborado e utilizado, é um documento valioso para aproximar o estudante do que se espera do estágio. Caminhando em sentido semelhante, Zabalza (2014) aponta para o manual como um referencial prévio, que constitua um projeto de curso e que seja, 
efetivamente, escrito (sair do campo das ideias) e tornado público a todos os envolvidos com o estágio, para que conheçam e assumam seus compromissos. Como diz o entrevistado: "Em termos de documentação, eu sei que existe no site da UFJF uma cartilha com várias orientações e tal, mas quando a gente chega para fazer os estágios ninguém fala que existe isso no site" (E3).

Segundo Zabalza (2014), para que o estágio possa ser compreendido como um projeto curricular que se integra à proposta curricular da carreira e cumpra com as suas funções, dois princípios fundamentais devem ser valorizados:

1) O nível de informatividade: que consista em um documento de fácil leitura e compreensão por parte dos estudantes a que se destina, que seja transparente; 2) A capacidade de orientação: não basta informar e deixar as informações claras. O plano de estágio deve orientar o processo de modo a antecipar as possíveis dificuldades, destacar os elementos centrais da experiência e orientar os estudantes sobre a forma de obter $O$ maior aproveitamento das práticas a serem realizadas (ZABALZA, 2014, p. 157).

No bojo da organização e do desenvolvimento do estágio, portanto, e em qualquer proposta a ele relacionada, como sublinha Zabalza (2014), as ações que se esperam dos envolvidos (professores orientadores, supervisores do estágio no campo profissional e estagiários) devem estar bem claras, não apenas no papel, mas, preferencialmente, discutidas entre as partes.

Decerto, professores orientadores e supervisores do estágio no campo profissional devem "compreender o sentido e os princípios dessa disciplina" (PIMENTA; LIMA, 2012, p. 126), além de assumirem a função de refletir com os seus estagiários "sobre as experiências que já trazem e projetar um novo conhecimento que ressignifique suas práticas" (PIMENTA; LIMA, 2012, p. 127), considerando as condições objetivas, a história e as relações de trabalho vividas. Trata-se de assertivas que merecem consideração, pois, cite-se como exemplo o que constata Lüdke (2013): supervisores do estágio no campo profissional se prontificam a assinar as folhas de frequência dos estagiários sem que eles estejam devidamente presentes em suas atividades (para se "verem livres deles"), com o argumento de que assumem densa carga-horária de trabalho e baseados na compreensão de que os estágios carecem de sentido.

Com efeito, os depoimentos retratam uma distância (já bem documentada na literatura sobre estágio) associada à conexão pretendida entre as instituições do campo profissional e a universidade; em nosso caso específico, entre as instituições do campo profissional e o trabalho de estágio realizado no interior do curso de bacharelado oferecido pela Faculdade de Educação Física e Desportos da UFJF:

Eu acho que as três bases, juntando o professor orientador do estágio com o estagiário em si e com o professor supervisor do estágio, deveria ter um acordo ali, alguma coisa. Não só no plano de atividades; não só uma coisa escrita que muitas vezes não é lida. Entendeu? Eu acho que a questão nesse método em si, esse ponto, 
PEREIRA, J. B.; BATISTA, D. P.; COELHO FILHO, C. A. A.

eu acho que fica muito distante, fica muito burocrático e pouco real, vamos dizer assim, pouco prático de fato (E6).

Para Zabalza (2011), a relação entre as instituições constitui uma variável importante do processo, e compreende que o funcionamento do estágio depende de uma cooperação institucional que se estabelece ancorada a elementos diversos:

La cooperación entre instituciones se produce en un marco de condiciones de naturaleza poliédrica. Las muchas caras de esa relación tienen que ver com aspectos legales (los convenios, la normativa aplicable, la limitaciones que impone el estatuto de estudiante en prácticas); administrativos (la adscripción de responsabilidades y tareas); laborales (la disponibilidad de tiempo de los tutores, las contraprestaciones, el tipo de trabajo que se puede o no se puede pedir a un estudiante en prácticas); profesionales (los contenidos formativos que se trabajarán, la rotación por diversas tareas profesionales); didácticos (la forma em que se ha de plantear la experiencia para que conduzca a un buen aprendizaje) e, incluso, personales (la relación entre el personal del centro de prácticas y los estudiantes, y la forma en que se afrontarán los conflictos si éstos se producen) (ZABALZA, 2011, p. 35).

Tendo por base os depoimentos coletados, interpretamos que a conexão entre as instituições, limitada a aspectos legais e administrativos, não contribui para que o estágio aflore em todo o seu potencial. Mas, ainda, sendo o vínculo (legal, administrativo) estabelecido entre as instituições do campo profissional e a universidade definido por essa, aquelas parecem assumir papel coadjuvante no processo de elaboração e desenvolvimento das atividades. Como resultado dessa condição, conforme Zabalza (2011), assinale-se o possível enfraquecimento do compromisso assumido pelas instituições concedentes de estágio, vendo-se seduzidas a apenas disponibilizar seus espaços para receber os estagiários e facilitar suas práticas.

O depoimento abaixo contribui para que possamos consolidar, um pouco mais, a interpretação, na medida em que sugere que a aproximação entre as instituições do campo profissional e a universidade, quando ocorre, extrapolando a burocracia legal, é por iniciativa dos próprios estagiários:

Essa relação depende muito do aluno também, do que ele vai fazer, de qual diálogo ele vai manter com aquela instituição onde ele vai buscar o estágio, com a universidade, como ele vai fazer essa ponte. Então, depende muito do aluno esse vínculo com a instituição concedente e a universidade. Esse ainda é um ponto falho (E2).

O tratamento dos dados nos leva a compreender que a relação entre o curso de bacharelado em educação física em questão e as instituições do campo profissional precisa ser ajustada e, tanto mais, qualificada. Que se promova uma interlocução que não se reduza, quiçá, como observa Calderano (2012), à simples prestação de serviços ao campo profissional, nem a cumprimento de horas previstas por parte do estagiário. 
Mas o problema do estágio se nos apresenta cada vez mais complexo, na medida mesmo em que a crítica se ramifica, seguindo direcionada para a seleção dos locais de estágio:

Esse negócio de a gente escolher o lugar que quer fazer o estágio também é um problema. Por um lado, é bom, porque aí você faz onde você tem mais interesse, ou é mais perto da sua casa. Mas as pessoas fazem estágio em lugares que assim... O estágio para mim, na verdade, não é o mesmo que para um colega meu, porque esse colega vai lá e assina, o amigo dele assina, o tio assina e está feito o estágio, e eu acho que não é bem por aí (E5).

Aqui, uma evidência merece ser registrada: os efeitos formativos dos estágios variam consistentemente em função das características materiais e funcionais das instituições onde são realizados (ZABALZA, 2014). O autor diz que embora seja possível extrair aprendizagens positivas de qualquer tipo de estágio, os desenvolvidos "em cenários estimulantes e enriquecedores deixam um estrato formativo muito maior, melhor organizado e mais duradouro" (ZABALZA, 2014, p. 136). Nesse sentido, Zabalza destaca dois tipos de características das instituições do campo profissional (centros de práticas), que se apresentam como espacialmente influentes: características materiais (extensão do local, localização, tipo de atividade desenvolvida, recursos disponíveis, entre outras); o estilo de funcionamento e a "cultura institucional" (estilo de liderança, hábitos de cooperação entre os profissionais, relacionamentos entre os colegas etc.).

Dito isso, e considerando, como indica o entrevistado, esse "negócio de a gente escolher o lugar que quer fazer o estágio" (E5), a leitura do trecho abaixo pode reforçar o dado empírico, e fazer soar o alerta:

Obviamente, nem sempre estamos em condições de poder escolher o melhor para nossos estudantes. No entanto, essas circunstâncias também não podem nos levar a desistir de ideia de que, podendo ou não, se trata de uma questão de relevância e que se contrapõe a certas práticas habituais em algumas universidades, como por exemplo:

- Deixar que os próprios alunos procurem e sejam eles os responsáveis por encontrar o centro em que desejam fazer as práticas.

- Estabelecer outros critérios de escolha: proximidade ao centro universitário, facilidade de deslocamento dos coordenadores, o hábito de ter trabalhado com eles anteriormente, entre outros fatores.

- Considerar que essa é uma questão sem importância e, portanto, desistir de assumir quaisquer critérios (ZABALZA, 2014, 136).

Elaborando o pensamento durante a entrevista, o estudante problematiza e, sendo assertivo, deixa entrever o otimismo do não existente:

Eu acho que o estágio deveria ser supervisionado. E eu acho que a faculdade poderia indicar os lugares. Assim, fazer uma reunião e falar, 
PEREIRA, J. B.; BATISTA, D. P.; COELHO FILHO, C. A. A.

sei lá: "nós temos vinte lugares, e nesses vinte lugares vocês vão fazer durante tal tempo. Nós vamos junto com vocês em tal dia". Marca no lugar para ter uma conversa, para supervisionar mesmo as atividades (E5).

Ao sugerir, nas entrelinhas, a necessidade de interlocução, organização e controle ("supervisionar mesmo"), o entrevistado nos remete para a compreensão de que o estágio pode se tornar um importante aliado para a formação, não apenas do futuro profissional (estagiário), mas também de professores orientadores e supervisores do estágio no campo profissional. O supervisor do estágio no campo profissional pode, por exemplo, como observam Pimenta e Lima (2012), desfrutar das possibilidades de o seu cotidiano profissional ser debatido, analisado e estudado, e nesse processo aproveitar para ressignificar sua prática e, até mesmo, sua identidade. As autoras alertam, portanto, para a necessidade de compreensão do sentido e dos princípios do estágio como formação continuada para os profissionais que estão envolvidos com a disciplina.

Portanto, quando o programa de estágio é organizado e desenvolvido privilegiando a interlocução permanente entre as instituições envolvidas (obviamente, entre os sujeitos artífices de tal processo), e percebido por elas como um campo primordial para a formação inicial (estagiário) e continuada (professores orientadores e supervisores do estágio no campo profissional), pode, quiçá, influenciar a mudança de posicionamentos e a tomada de conscientização acerca de ações que mereçam ser repensadas e ajustadas. Decerto, nesse diapasão, a responsabilidade de professores orientadores e supervisores do estágio no campo profissional deve ser sublinhada.

Diante do exposto, há de se compreender a responsabilidade assumida por professores orientadores e supervisores do estágio no campo profissional para que uma estrutura de estágio, carente de qualidade e organização, se instale e ali permaneça. De todo modo, não podemos deixar de postular, com Zeichner (2010) e Pires (2012), a existência de condições desfavoráveis para se trabalhar com os estagiários, enfrentadas por esses artífices do processo. Trata-se de postulado que aponta para a necessidade de desdobramento desta pesquisa, especificamente, para estudos em que os dados empíricos provenham dos discursos de quem é responsável por acompanhar os estagiários na universidade e no campo profissional.

\section{CONSIDERAÇÕES FINAIS}

Tendo em vista a análise e a interpretação dos dados empíricos coletados no presente estudo, destacamos as seguintes conclusões:

Constatam-se problemas organizativos associados ao estágio oferecido pelo curso de bacharelado em educação física da FAEFID/UFJF. Se, de um lado, os entrevistados sugerem e desvelam almejar, de forma mais ou menos explícita, uma conexão que podemos denominar de mais qualitativa, entre a universidade e o campo profissional, de outro os seus discursos evidenciam se estabelecer entre as instituições formadoras de estágio uma relação em que, tendenciosamente, a dimensão burocráticoadministrativa representa o seu único fim e sustento.

A conexão entre as instituições do campo profissional e a universidade, limitada a aspectos legais e administrativos, não contribui para que o estágio aflore em todo o seu 
potencial. Trata-se de uma conexão que, quando ocorre, extrapolando a burocracia legal, é por iniciativa dos próprios estagiários.

Os entrevistados vivenciam momentos de tensão ao lidar com a documentação necessária para a formalização e realização dos estágios. É uma burocracia que pode impactar por conta das possibilidades de atraso no início do estágio e até mesmo a sua não conclusão no semestre letivo, o que implica nova matrícula na disciplina em semestre subsequente e novo encaminhamento de documentação.

Em que pese o longo caminho a ser trilhado pelos alunos para o cumprimento das horas de estágio, constata-se que as dificuldades relacionadas às orientações emergem antes mesmo de a jornada ter, objetivamente, iniciado. Evidencia-se, assim, uma falha nas estratégias adotadas pelo curso em questão, e em especial pelos responsáveis a orientar os discentes no interior deste curso, quanto à iniciação no estágio, associada especialmente à lida com os documentos exigidos, e à burocracia. Nesse diapasão, deve-se observar que os documentos oficiais, quando adequadamente pensados, disponibilizados e utilizados no contexto do estágio, contribuem com a orientação dos estagiários e organização da disciplina.

Há de se compreender a responsabilidade assumida por professores orientadores e supervisores do estágio no campo profissional, para que uma estrutura de estágio carente de qualidade e organização se instale e ali permaneça. Não podemos deixar de postular, contudo, a existência de condições desfavoráveis para se trabalhar com os estagiários, enfrentadas por esses artífices do processo.

Por fim, queremos destacar a importância das constatações do presente estudo, que coloca em discussão o estágio obrigatório oferecido por um curso de bacharelado em educação física, tendo como suporte empírico o discurso de estagiários. Em termos amplos, os resultados desta pesquisa talvez possam fornecer subsídios para que o estágio, em articulação com o campo profissional, possa se efetivar com a qualidade almejada nas instituições de ensino superior, auxiliando como se espera com o processo formativo do graduando. Entendemos e identificamos que há a necessidade de novos estudos sobre a temática do estágio nos cursos de bacharelado, com a busca por aprofundamentos e por diálogo com as questões que estão postas. Compreendemos também a necessidade de se realizar pesquisas que evidenciem as situações enfrentadas por professores orientadores e supervisores do estágio no campo profissional em cursos de bacharelado, a partir do ponto de vista deles.

\section{THE MANDATORY IN A BACHELOR'S DEGREE IN PHYSICAL EDUCATION}

ABSTRACT:This research aims to discuss the mandatory internship offered by the Bachelor's Degree in Physical Education at the Federal University of Juiz de Fora, focusing on the contributions and 
PEREIRA, J. B.; BATISTA, D. P.; COELHO FILHO, C. A. A.

limitations associated with the professional training process. Ten undergraduate students who had already completed at least two mandatory internship subjects in the program were interviewed. Principles of the comprehensive interview guided the procedures of data collection, analysis and interpretation. We conclude that the connection between the institutions of the professional field and the university, limited to legal and administrative aspects, does not contribute to the internship to emerge to its full potential.

KEYWORDS: Education. Physical Education. Internship. Professional training.

\section{LA PASANTÍA OBRIGATORIA EN UN CURSO DE BACHILLERATO EN EDUCACIÓN FÍSICA}

RESUMEN: Esta investigación objetiva discutir la pasantía obligatoria ofrecida por el curso de bachillerato en educación física de la Universidad Federal de Juiz de Fora, con su foco direccionado a las contribuciones y limitaciones asociadas al proceso de formación profesional. Diez graduandos que ya habían cumplido, como mínimo, dos asignaturas de pasantía obligatoria en el curso, fueron entrevistados. Los principios de la entrevista comprensiva orientaron los procedimientos de recolección, análisis e interpretación de datos. Concluimos que la conexión entre las instituciones del campo profesional y la universidad, limitada a aspectos legales y administrativos, no contribuye a que la pasantía aflore en todo su potencial.

PALABRAS CLAVE: Educación. Educación Física. Pasantía. Formación profesional.

\section{NOTAS}

1) Com o termo (Practicum), o autor se refere ao período de práticas formativas incluído nos cursos universitários. Especificamente, "destinado a enriquecer la formación complementando los aprendizajes académicos (teóricos y prácticos) con la experiencia (también formativa, es decir, vinculada a aprendizajes) en centros de trabajo" (ZABALZA, 2011, p. 26).

2) Em Zeichner (2010), professor supervisorrefere-se ao docente que atua na escola. Nesta pesquisa, utilizamos o termo supervisor do estágio no campo profissional para identificar o profissional que supervisiona o trabalho do estagiário na instituição concedente (por exemplo, academia de ginástica), e professor orientador para identificar o responsável pela disciplina de estágio na universidade.

3) Como o foco do nosso estudo é o estágio na formação inicial do profissional de educação física (bacharel) e não do professor de educação física (licenciado), importa registrar a relevância assumida por Zabalza $(2011 ; 2014)$ nas interpretações que encaminhamos.

4) Pimenta (1995), tendo por base Marx, compreende como práxis "a atitude (teórico-prática) humana de transformação da natureza e da sociedade. Não basta conhecer e interpretar o mundo (teórico), é preciso transformá-lo (práxis)" (p. 86).

5) Os estágios são iniciados a partir do $5^{\circ}$ período, podendo-se cursar três disciplinas estágio, de cinquenta horas cada uma. No $6^{\circ}$ período se repete o mesmo procedimento, com a orientação de que esses estágios sejam realizados em áreas diferentes dos anteriores. No $7^{\circ}$ e $8^{\circ}$ períodos são exigidos dois estágios, de cem horas cada um. Ao final do curso, deve-se computar quinhentas horas de estágio. 


\section{REFERÊNCIAS}

AGOSTINI, S. A organização e o desenvolvimento de estágios curriculares em cursos de licenciatura da UFSM: envolvimentos de estagiários e orientadores.2008. 281f. Dissertação (Mestrado em Educação) - Programa de Pós-Graduação em Educação, Universidade Federal de Santa Maria, Santa Maria, 2008.

BRASIL. Lei no 11.788 de 25 de setembro de 2008. Dispõe sobre o estágio de estudantes. Diário Oficial da União, Poder Executivo, Brasília, DF, 26 de setembro de 2008. Seção 1, p. 3.

CALDERANO, M. da A. O estágio curricular e os cursos de formação de professores: desafios de uma proposta orgânica. In: CALDERANO, M. da A. (Org.). Estágio curricular. concepções, reflexões teórico-práticas e proposições. Juiz de Fora: Editora UFJF, 2012.

CALDERANO, M. da A. Tecendo relações entre teses e ações desenvolvidas por professores supervisores de estágio curricular. In: 36a REUNIÃO NACIONAL DA ANPED; 2013, Goiânia-GO. Anais... Disponível em:

$<$ http://www.36reuniao.anped.org.br/pdfs_trabalhos_aprovados/gt08_trabalhos_pdfs/ gt08_2668_texto.pdf>. Acesso em: 17 mar. 2018.

GATTI, B. A. Formação de professores no Brasil: características e problemas. Educação \& Sociedade, Campinas, v. 31, n. 113, p. 1355-1379, out./dez. 2010.

GATTI, B. A.; BARRETO, E. S. de S. Professores do Brasil: impasses e desafios. Brasília: Unesco, 2009.

KAUFMANN, J. C. A entrevista compreensiva: um guia para pesquisa de campo. Tradução Thiago de Abreu e Lima Florencio. Petrópolis, RJ: Vozes; Maceió: Edufal, 2013.

KULCSAR, R. O estágio supervisionado como atividade integradora. In: PICONEZ, S. C. B. (Org.). A prática de ensino e o estágio supervisionado. Campinas: Papirus, 1994.

LÜDKE, M. O lugar do estágio na formação de professores. Educação em Perspectiva, Viçosa, v. 4, n. 1, p. 111-133, jan./jun. 2013.

PEREIRA, R. C. B.; PEREIRA, R. de O. O estágio supervisionado no contexto da formação de professores. In: CALDERANO, M. da A. (Org.). Estágio curricular. concepções, reflexões teórico-práticas e proposições. Juiz de Fora: Editora UFJF, 2012. p. 21-33.

PIMENTA, S. G. O estágio na formação de professores: unidade teoria e prática? 2. ed. São Paulo: Cortez, 1995. 
PEREIRA, J. B.; BATISTA, D. P.; COELHO FILHO, C. A. A.

PIMENTA, S. G.; LIMA, M. S. L. Estágio e docência: diferentes concepções. Poíesis Pedagógica, Catalão-GO, v. 3, n. 3-4, p. 5-24, jul. 2006.

PIMENTA, S. G; LIMA, M. S. L. Estágio e docência. 7. ed. São Paulo: Cortez, 2012.

PIRES, F. C. de O. O papel do professor orientador na efetiva-ação do estágio: múltiplas visões. In: CALDERANO, M. da A. (Org.). Estágio curricular. concepções, reflexões teóricopráticas e proposições. Juiz de Fora: Editora UFJF, 2012. p. 169-184.

SOUSA, J. N. de; LESSA, P. B. Estágio supervisionado a distância: experiência do curso de pedagogia-UAB/UFJF. In: CALDERANO, M. da A. (Org.). Estágio curricular. concepções, reflexões teórico-práticas e proposições. Juiz de Fora: Editora UFJF, 2012. p. 145-168.

UNIVERSIDADE FEDERAL DE JUIZ DE FORA. Manual de estágio COEFAEFID. A proposta atual do estágio obrigatório em Educação Física Bacharelado. 2010. Disponível em: <http://www.ufjf.br/ufjf?s=manual+de+est\%C3\%A1gio >. Acesso em: 22 out. 2018.

UNIVERSIDADE FEDERAL DE JUIZ DE FORA. Regulamento Acadêmico da Graduação RAG. 2016. Disponível em: <http://www.uff.br/prograd/files/2009/02/NOVO-RAG21.07.pdf>. Acesso em: 22 out. 2018.

ZABALZA, M. A. El Practicum en la formación universitaria: estado de la cuestión. Revista de Educación, Santiago Compostela, v. 354, p. 21-43, jan./abr. 2011.

ZABALZA, M. A. O estágio e as práticas em contextos profissionais na formação universitária. Tradução Sandra Trabucco Valenzuela. São Paulo: Cortez, 2014.

ZEICHNER, K. Repensando as conexões entre a formação na universidade e as experiências de campo na formação de professores em faculdades e universidades. Educação, Santa Maria, v. 35, n. 3, p. 479-504, nov. 2010.

Jonathan Barra Pereira: Bacharel em Educação Física pela Universidade Federal de Juiz de Fora. Bolsista no Colégio de Aplicação João XXIII da UFJF. Temas de interesse: educação física escolar; estágio curricular.

Orcid: https://orcid. org/0000-0002-1515-9503

E-mail: jonathanbarra_157@hotmail.com

Deniele Pereira Batista: Professora do Colégio de Aplicação João XXIII, da Universidade Federal de Juiz de Fora. Doutora em Educação pela Universidade Católica de Petrópolis. Integrante do Grupo de Estudos sobre Profissão Docente (GEProf). Temas de interesse: formação de professores; prática pedagógica; experiência; profisssionalidade docente; anos iniciais do ensino fundamental; saberes docentes.

Orcid: https://orcid.org/0000-0001-7159-0106

E-mail: deniele.batista@ufjf.edu.br 
Carlos Alberto de Andrade Coelho Filho: Professor Associado da Universidade Federal de Juiz de Fora/Faculdade de Educação Física e Desportos. Doutor em Psicologia Social pela Universidade do Estado do Rio de Janeiro. Temas de interesse: formação do professor e do profissional de Educação Física; prática profissional em Educação Física; motivação para a prática regular de atividades físico-esportivas; corpo; psicanálise.

Orcid: https://orcid. org/0000-0002-3417-2033

E-mail:carlos.coelho@ujif.edu.br

Este periódico utiliza a licença Creative Commons Attribution 3.0, para periódicos de acesso aberto (Open Archives Iniciative - OAI). 